\title{
AFGHANISTAN AGRICULTURAL SECTOR SUPPORT PROJECT
}

\section{PRIVATE SECTOR AGRIBUSINESS \\ (ASSP/PSA)}

\author{
TRAINING STRATEGY FOR \\ AGRICULTURAL WORKERS IN \\ AFGHANISTAN
}

Prepared for

OFFICE OF THE AID REPRESENTATIVE

FOR AFGHANISTAN (O/AID/REP)

Prepared by

Rodney J. Fink, Ph.D.

November 1992 


\title{
AFGHANISTAN AGRICULTURAL SECTOR SUPPORT PROJECT
}

\section{PRIVATE SECTOR AGRIBUSINESS (ASSP/PSA)}

\author{
TRAINING STRATEGY FOR \\ AGRICULTURAL WORKERS IN \\ AFGHANISTAN
}

Prepared for

OFFICE OF THE AID REPRESENTATIVE

FOR AFGHANISTAN (O/AID/REP)

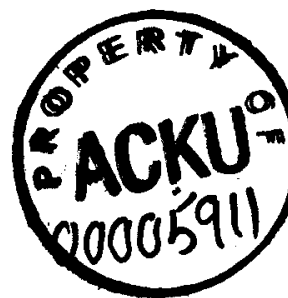

Prepared by

Rodney J. Fink, Ph.D.

November 1992 


\section{TABLE OF CONTENTS}

I. Summary of Recommendations

Page $=$

II. Scope of Work

1

5

6

IV. Strategy for Development of Human Resources 8

V. Annual Winter ADT Training Program

VI. Utilization of Pakistan Facilities and

Professional for an Instructional/Support Role.

VII. Summary and Recommendations.

APPENDIXES

I. Daily Activities of Training Consultant

II. Program for Shura/NGO Personnel

III. Budget for Shura/NGO Personnel

20

IV. Program for Afghan Managers (on hold)

\section{Acknowledgements}

The consultant would like to acknowledge the understanding, help and advice provided by DAI staff in Islamabad and Peshawar. All phases of support including office, transportation, staff and pakistan productive and enjoyabled on demand and made the stay in 


\section{SUMMARX OF RECOMMENDATIONS}

Rodney J. Fink was in Pakistan from sept. 28 to october 30 1992 as a DAI consultant to ASSP/ADT. The early weeks of the period were spent acquainting ADT staff with organizations in Pakistan with professionals capable of assisting with ADT training programs. Concurrently, he assisted with planning for two workshops for Afghan Agriculturalists nominated by shura or non government organizations (NGO). The final periods of time were spent helping plan training for ADT extension workers stationed in Afghanistan (annual winter training program), developing a training strategy and assisting with impiementation of the shura/NGO training plans. The recommendations put forth are detailed in the following sections.

\section{Recommendations}

* I'raining programs for ADT staff should be planned on an annual basis. Since training is held early in the year, the annilal training plan should commence following each training cycle and outlined in advance with a "Scope of Work" stating training objectives and the action needea to meet these objectives.

* More training should be planned inside Afghanistan to be carried out primarily by the extension agents assigned inside the country. ADT support staff should develop materials to support this activity.

* In-country staff training should be more specialized in order to provide each extension center more qualified personnel. Specialized training in integrated pest management, fertility, seed technology, irrigation, management, etc. would add credibility to in-countr. staff. Resources should be concentrated on several successful centers to develop expertise for a "train the trainers" approach for enhancing technology transfer.

* Expanded lise of Pakistan centers of expertise such as the National Agricultural Research Center, Ayub Agricultural Research Institute and the NWFP Agricultural University should be utilized for training and professiona] linkages. ADT staff should provide counterpart staff to assist planning of training programs. 
Training for agriculturalists other thar. AD'T extension staff is encouraged but should be built into the annual plan of work so as not to overload the staff with excess training programs at one time. Work with personnel who are likely to become leaders in agriculture at the central government level is encouraged when possible and politically practical. Linkages between such officials and the extension centers of ADT should hopefully be
developed in the future.

* Newly appointed extension

should have an introductory agents in the northern areds 1993 and then be integrated training course in January, courses of other agents.

* ADT extension officers and supervisors should have management training including experience in preparing work plans and an annual scope of work. The final week: of a management workshop might be an appropriate time for extension officers and ADT support staff to worl: together to plan an annual scope of work. Since many educational materials are written in English, the English ability of extension officers and supervisors should be evaluated and if needed, they should be offered an intensive (four weeks) English course. 


\section{SCOPE OF WORK}

The Agricultural. Development and Training (ADT) component of the Afghanistan Agricultural sector support Project is developing training objectives and a training strategy for the transitiona period into Afghanistan. This program will include participation of as many as 150 individuals who have been working in Agriculture in Afghanistan in major food producing areas. ADT will continue its in service training program for 100 ADT field staff working in Afghanistan. Specifically ADT needs help to do the following.

1. Plan the annual winter ADT training program. specific: attention needs to be given to new personnel working in the Northern Provinces. These should be specific sessions designated for future planning for agricultural development in
Afghanistan.

2. Develop training objectives and a plan for integrating up to 150 agriculturists into our annual training program. People will be targeted who have been working in Afghanistan in Agriculture but who have not had an opportunity to upgrade their skills over the last 14 years.

3. Involve qualified Pakistani technicians who represent major agricultural disciplines and organizations in the training program. The linkages between the agriculturist in Afghanistan and Pakistan needs to be renewed.

4. Help in the development of a strategy for ADT to begin the transition into Afghanistan. This should include structure and method of operation. 


\section{THE CURRENT SITUATION}

The Agricultural Development and Training component (ADT) of the Afghanistan Agricultural sector support project (AASP) has conducted a program of training for project employees working as extension agents inside Afghanistan. Many short, single purpose courses have been conducted and in early 1992, 110 ADT agriculturalists participated in a 12 week training course in the NWFP with side trips to Lahore and Quetta. Training has been provided in many subject areas including horticulture, cereal production (plant protection, fertility, seed multiplication, etc.), plant propagation, farm machinery, water harvesting, machinery operation, management, extension methodology, marketing, vegetables and other related areas. The training has been designed to support the introduction of improved varieties, cultivars, equipment, fertilizer, extension activities and other components of production inside Afghanistan. Training has been provided to the majority of the approximately 180 regular and contract employees of the project stationed inside Afghanistan.

To support the workers inside Afghanistan, technical staff are located in Pakistan (Islamabad, Peshawar and Quetta) to provide technical training and logistical support. The staff includes many Afghans who are well qualified and motivated for their work.

The past training activities of ADT have been primarily for their own extension staff. Several workshops, especially some programs for fruit and vegetable workers, have accepted trainees from other NGO's. Recognizing the need for additional training for Afghan agricultural workers, plans are now in progress to train other Afghan groups. ADT staff members (primarily Afghan or of Afghan origin), are well qualified in their disciplines and deliver a substantial portion of the training themselves. Assuming the project staff is able to move into Afghanistan, the current staff can make a major contribution by training Afghan agriculturalists. Training to date has been appropriately general in nature and directed to the major commodities the project works with (wheat, maize, rice, potatoes, fruit, vegetables, and farm machinery) to support such production. Future training for AD'T staff should provide greater depth of training for employees working in Afghanistan, by developing a corp of extension workers with individual specialties (integrated pest management, soil fertility, seed propagation and maintenance, cultural practices, extension methodology). These people can become the trainers in a "train the trainers" program to expand agricultural knowledge to other Afghan
agriculturalists. 
On arrival at DAI in Islamabad, initial efforts were spent developing training programs for non-DAI employees nominated by Shuras and by iCO's (150 participants) and a program tor managerial personnel from Afghanistan (65 participants). My work counterpart was Qasim Yusufi, a well qualified trainer who understands the Afghan problems and has a good grasp of training needs. The status of the Shura/NGO program and the program for managers follows:

1. Afghan shura and NGO personnel; The program budget and plan has been completed and contacts for instruction completed. Plans are made to begin this program on Nov. 20 (see Appendix II). The budget for the program was prepared and submitted. (see Appendix III).

2. Afghan Managers Program: This program was planned simultaneously with the Shura/NGO program and although tentative plans were for an offering beginning in late October, at this time plans for offering the course are pending. The course program (see Appendix IV.) and budget (see Appendix V.) are completed. The courso was developed specifically for managers of agricultural programs in positions that might provide direction for agricultural development in Afghanistan. In addition to orientation and debriefing of the participants, the program contained the following training modules:

A. Agriculture research, outreach, extension and the technology transfer process: This program (one week) will enable participants to see the agricultural activities of the NWFP of Pakistan. The program is to be coordinated through the NWFP Agricultural University and includes the educational system, research system, outreach and continuing education, extension and information services. The technology transfer process in place in NWFP is a major thrust of the program as is an overview of the cereals work (and related soil fertility, plant protection, culture, varieties, etc.) and extension methods used in transferring technology.

B. Program management workshop: This workshop was developed specifically for this group of workers through consultation with save the children, U.K. (Peshawar). Topics such as leadership, management, program planning and evaluation were selected for use in a participatory environment. Group size is to be limited to no more than 16 participants. Save the Children, U.K. has been offering such programs in peshawar for many years and is very competent in developing a program to meet specific manacjement group needs. 
C. Agricultural progress in the Quetta area: Quetta was selected as an important area for these participants due to the similarity of agriculture and due to the presence of the Arid Zone Research Institute and the Saryab Research Institute. DAI staff in Quetta provide support and help with arrangements for the programming. The bus trip to Quetta provides additional opportunity for stops (D.I. Khan for example) to see appropriate agricultural technology.

D. The Punjab (Lahore and Faisalabad area) seed processing, machinery manufacturing and cereals update: This field trip is especially appropriate because it updates participants on the seed industry in Pakistan (Pioneer and Cargill seed plants), the equipment industry (Milat, Batala and Naeem) and the Ayub Agriculture Research Institute in Faisalabad. This week of training will expose the participants to the private seed and equipment industry that has developed in the punjab and the status of research, training and technology transfer taking place through the Ayub Agricultural Research Institute and other agencies.

The program is in place and can be activated on a short notice. If the duration of the program needs to be shortened, any one of the modules could be deleted and a $1,2,3$, or 4 week offering made. The inclusion of a one day stop at the National Agricultural Research Center in Islamabad would be a useful addition to the program and colld be managed easily by a slight diversion of route during one of the two field tours. Part of the scope of Work of this assignment was to involve qualified Pakistani technicians in the training program and where possible, link appropriate agriculturalists in Afghanistan with counterparts in Afghanistan. This program effectively provides linkage opportunities for counterparts of the two countries.

\section{Strategy for Development of Human Resources}

By identifying and carefully selecting employees, ADT has a competent group of employees carrying out extension work inside Afghanistan. Through the annual winter training program, they have been exposed to current technology available throughout Pakistan. Through the experience of working with the supplied inputs (seeds, fertilizers, equipment) and interaction with Afghanistan farmers, they have probably become one of the better qualified groups of information transfer agents inside Afghanistan. To maximize output from these people, they will need greater depth and breadth in their knowledge base. This can best be provided by developing specialization among the members of each extension center. Not 
only do the agents need to provide information to farmers on a regular basis, they should be trained well enough to be trainers to other extension offices. The development of a "Train the Trainer" program, composed of well qualified trainers could significantly expand the sphere of influence of this training effort. The following example could be the scheme appropriate for a given extension center with an extension officer (general agent and coordinator) and 5 agents, all serving as generalists to their clientele:

\section{Extension Center Personnel}

Extension Officer - Admin./planning
Agent 1 - Seed \& Agronomy Specialist
Agent 2 - Plant Protection Specialist
Agent 3 - Soil Management/Fertility Specialist
Agent 4 - Water Management Specialist
Agent 5 - Farm Management Specialist

All agents would serve as generalists but specialized training would allow each agent to serve in the role of being a specialist as well. The center could serve not only in a "trouble shooting" role but also take on an "educational role" for training personnel in other centers. As each agent becomes better trained in their area of specialty, they can expand ability to serve by taking an active educational role to serve other centers. When agents are well trained and experienced in their specialty, they should be able to prepare bulletins and other educational materials for literate clientele and other agents. Some centers could eventually be equipped to take the role of a "media center".

When the government in Afghanistan has established a stable Ministry of Agriculture, contact and liaison needs be established. For sustainability, the channelling of training and inputs should be through the Ministry channels and the availability of functioning, well-staffed centers could be attractive to appropriate government personnel. Such centers could be "pilot centers" and provide an example for implementation in other areas of the country. If other avenues of extension education are implemented by the Kabul government, the presence of well-trained personnel in the ADT centers could be a source of trained personnel.

ADT should move more of their training programs into Afghanistan. The extension offices in the country should become the main site of educational activity. To do this, specialized training will be needed for current agents and some training courses developed which will help the in-country staff put on their own workshops. ADT staff who support the extension agents could prepare additional educational materials (in addition to utiliaing those now prepared) that the in-country staff can utilize. Many visual materials are available to support production of the crops being grown so ADT support staff could prepare slide sets, brochures and other materials in Dari or Pushto and prepare "canned programs" for use by in-country extension agents. Several 
extension centers should be selected (those with the best capability) to be the pilot program leaders in such activities.

Training efforts for current extension staff should center on specialized expertise to support their ability to provide better "in-country training".

When government personnel in agriculture are identified, contacts should prove productive in perpetuating the current program. By providing potential agricultural leaders (such as ministry personnel) training, the continuation of education and inputs (fertilizer, seed, education, etc.) could be continued and hopefully expanded when normalization of government operations commences. When the agricultural organization in the country is capable of operation, the inputs and coordination of training should be promulgated through the government channels. By being in touch with the appropriate government personnel, the project could have a greater chance to influence the establishment of a workable system. If personnel of the Afghan Agricultural Ministry (or people likely to be in the Ministry) are available for training, ADT should work with them to determine possibilities for the future as well as identify problems which affect agricultural production , including not only the limit of inputs but the limitations of the current (or soon to be established) infrastructure.

Educational programs require a vision and a plan to support the vision. Training programs should be planned well in advance to meet the project objectives and time available for training. The ADT training schedule has generally been from mid-December through min-March. Planning for the January to March, 1993 program is now underway. Planning should be done on a year round basis so advance arrangements could be more easily accomplished. The planning cycle should probably run from March through February with February, 1993 being the time to begin planning the training program for early 1994. Training plans should parallel other objectives of the project and be considered together. Periods of in-country training will differ depending on peak and seasonal work loads of the region. The planning scheme might look as follows (keeping in mind that this is only an example and will need to be developed by joint planning effort of staff):

Time of year Training Activity/planning time Jan and Feb. Training time for ADT personnel March Planning time for ADT Project program personnel. Input should be used from the participants of the ADT (in-country) staff. Plans should include training for ADT staff and in-country training by ADT staff.

Apr.-Jun

Headquarters staff prepare lesson materials for in-country workers. Short course materials (of courses to be offered in Afghanistan) should be prepared. 


$\begin{array}{ll}\text { Jul. Aug. } & \text { Headquarters staff plan the annual winter } \\ \text { training program for in-country staff (to } \\ \text { take place in Jan. and Feb.) } \\ \text { sept.-oct. } \\ \text { In-country staff conduct short courses } \\ \text { and other in-country training efforts. } \\ \text { ADT headquarters staff provide support to } \\ \text { them. } \\ \text { Extension staff (in-country) develop their } \\ \text { priority objectives for training they will } \\ \text { provide (in-country) during the next year. } \\ \text { ADT headquarters staff make final } \\ \text { preparations for Jan.- March training and } \\ \text { pec. } \\ \text { Tranning session. } \\ \text { Jan.- Dec. }\end{array}$

Northern Area Personnel (new appointees): Personnel have been recently assigned to the Northern provinces who have not been through previous training cycles. These employees should have a different training orientation than the longer term employees. The Balkh, Baghlan, Samangan, Kunduz \& Takhar have at least 16 new extension agents. The following program is recommended for them:

Recommended training component

1. Briefing by DAI personnel about the program

operation, expectations and responsibilities.

Through interaction with DAI staff, develop

information about their regions, current status

of agriculture and needs of these people for

successful work.

Duration

2. Develop the concept of "team work" within

the group by enrolling them in a community

Participation Workshop. Zone and area

supervisors should participate with them.

Recommend Save the Children to offer the

workshop.

$1 \operatorname{lnok}$

3. Organize a cereal crops workshop utilizing

1 week

ADT staff and assistance from personnel of

the Cereal Crops Research Institute (Pirsabak) 1 week

or NARC (Islamabad)

4. Provide a field trip to the Lahore area to

visit Pioneer, Cargill, Milat, Naeem, \& Batala

Industries and the Ayub Agricultural Research

Institute. On return from Lahore, spend 2 days

at the National Agricultural Research Center

in Islamabad.

1.5 weeks

After completing this training program, these participants would be ready to enter other more specialized programs provided for other ADT personnel during Feb. and Mar., 1993. 
Programs for non-Northern areas: strategy for continuing training program: With the exception of some specialized courses (fruit drying, equipment operation, etc.), The winter training has been general in nature and participants have received similar programs (although special courses have been given to machinery operators, etc.). In order to build a capability with greater depth of knowledge, specialized training should be provided to participants in a systematic manner so that each region will have a trained person in as many areas as are practical and needed (for example integrated pest management\{IPM\}, integrated nutrient management, program management and planning, rice culture, etc.). The following courses are recommended for the ADT winter training session. Participants from the Northern areas who have completed their course could also participate in the following training courses as appropriate.

1. Extension officers English Training course: Much of the new information available to extension people is in English. The ability to attend courses and interpret journals/papers in English will enhance the capability of extension people. An English course, specializing in conversation and reading would enable the extension officers (head person in each office and area and supervisory personnel) to be more effective officers. The course should be offered in Jan. while the Northern area people are in their training program. Many well qualified English teachers are available who could lead a group of about 20 people through a good course. The course should be an intensive course with 4 to 6 hours of daily training and practice lasting for a period of 4 consecutive weeks.

2. Extension officers leadership, management and planning workshop: Extension officers will become more involved with management and planning and thus need more tools to work with. A custom designed program for this group should be developed to provide a program management component with general groupings under the sections of leadership (including motivation, group skills and interpersonal skills), management (including principles of management, delegation of responsibility, group organization, supervision and follow up) and planning (principles of planning, report writing, developing a work plan). With planning assistance from ADT staff, the Save the children, U.K. staff (and other NGO staff in Pakistan) could provide such a program as could personnel of the Lahore University of Management Sciences (IUMS) or other Pakistan based organizations. Personnel could be brought in from the U.S. or other countries qualified and experienced in carrying out such programs. The concluding periods of the workshop could serve to develop a plan of work for each of the work districts in the country. Those responsible for program planning in ADT 
might well be participants in the planning session and work to develop a unified ADT plan for the year. This program should be scheduled for a 3 week period (although some adjustment - shorter or longer - could be considered.

Instructional contact: Suggest first contact for offering the course be made with save The Children, U.K. Second choict would be Lahore University of Management Sciences (LUMS) or other NGO or Pakistani organizations (Peat Marwick and Co. (Karachi) or Pakistan Institute of Management (Lahore) for example.

3. Developing a plant protection program using principles of Integrated pest Management(IPM) : Pest control (weeds, insects, diseases, arthropod and vertebrate pests are stated to be major problems in Afghanistan. Reliance on chemical methods of control is expensive, potentially harmful to the environment and often not practical because proper pesticides are not available. IPM seeks to control pre and post harvest weeds, arthropod and vertebrate pests and pathogens using biological and cultural techniques along with minimal levels of synthetic pesticides. Rather than employing indiscriminate spraying programs, a system of pest scouting needs to be in place to discover problems and make the appropriate treatment only when a damage threshold level is reached. Thus to be a qualified IPM specialist a thorough knowledge of plant protection techniques is necessary. Personnel from each office (generally one per office) should be selected to develop leadership in plant protection using principles of IPM. These trained people would then be responsible for training others in their region on these principles of plant protection through Integrated Pest Management. The program developed should include at least the following components:

A. Principles of plant pest control

B. Methods of plant pest control (biological, mechanical, cultural, chemical)

C. Principles of pesticide application (sprayer calibration, spray safety, safety hazards, proper labeling, following instructions, protective clothing, etc.)

D. Summary sessions on the diseases, insects, weed and other pests attacking crops in areas served (must include ldentification, methods of control, threshold levels of loss, etc.)

E. Pest control for stored grains, fruits, vegetables, etc. F. Principles of Integrated Pest Management (must include the interaction between different pests and offer alternatives to be employed which will enable non-chemical, or at least minimal use of chemical pesticides. Emphasis should be on biological, cultural, mechanical methods of control.

G. The role of scouting in a program of IPM. 
The program should be a 3 to 4 week program spending about one-half of the time on learning principles and

identification of plant and pests and the remainder of time devoted to integrating control measures using principles of IPM.

Instructional Contact: The NWFP Agricultural University System has well qualified personnel in IPM. Several experienced faculty/researchers have recently returned from the United States with new Ph.D degrees and are up to date for the implementation of an IPM program. A team taught course (entomologist, pathologist, weed scientist) working together under the framework of an IPM program would be very effective in providing this instruction.

4. Soil Fertility/Integrated Nutrition Management Workshop: The ADT program ships quantities of fertilizer to Afghanistan to improve the grain production. The proper use of fertilizers requires a good understanding of plant needs and environmental factors such as soil/plant interactions. Plant nutrients should be provided to crops through a program of integrated nutrient management which involves optimal use of on-farm biological resources (including manures, plant rotations, cropping patterns, and legumes) and, where necessary, acquired fertilizer inputs. A short course covering the principles of soil fertility including an introduction to soil testing would help extension personnel make more valid recommendations to farmers and thus effectively increase yields using minimal purchased inputs. Such a course should be 2 to 3 weeks in length and cover principles of soil and plant nutrition, nutrient uptake, sources of nutrients, factors affecting release of nutrients, identification of plant deficiency symptoms. The course should be about three weeks in length and include both classroom, laboratory and field work.

Instructional contact: Members of the NWFP AU system are capable of doing a nice job on such a course. Faculty from the campus and Research system could join together and teach this course. The program in soil and plant Nutrition operated from Tarnab under Habib Ur Rehman (with good help of saeed Ahmad) should be included in such a program of instruction. 5. Principles of effective water management and conservation: Irrigation systems are a component of much of the agricultural land in Afghanistan. A basic course in water management is needed to teach participants the water measurement, infiltration, irrigation scheduling and conservation and provide guidelines on the rehabilitation of irrigation systems. Students should develop a better understanding of the interrelationship between soil, plants and water supply. This course should be 2 to 4 weeks in length. 
Instructional contact: Dr. Jamal of the soil and Water Management Department of the NWFP AU, is the logical contact for this course. He is qualified and able to meet the instructional needs of these agents. NARC could also offer such a course.

6. Seed Technology for Extension workers: Since introduction of improved varieties is a major component of the ADT/AASSP, improved skills in growing, processing, maintaining and distributing seeds is appropriate. Not only is introduction of good seed important, ability to maintain quality control on seeds is required. A short course designed to cover major aspects of seed technology would be useful to ADT employees. The course should cover methods of seed testing that can be done with minimum equipment so as to be appropriate technology for the students. Purity standards, germination determination, storage methods, principles of increasing and maintaining seed stocks would be included as would information on the storage and maintenance of good seed. Emphasis would be on procedures for cereal crops but the principles would apply to all crops. The course of 5 days duration would be designed to meet the needs and conditions present in Afghanistan.

Instructional Contact: Dr. Bashir Ahmad of the NWFP Ag. Univ. has a Ph.D in seed Technology and is well qualified to offer such a course. Staff of NARC could also offer the course. 7. Rice Update for Agents from Rice Growing Regions: Agents from Nangarhar, Takhar, and Baghlan (rice producing regions) are involved in rice production. A one week short course to assist these workers would be appropriate. An intensive: course covering varieties, techniques of planting (transplant vs. direct seeding), fertility requirements, disease, insect, and weed control and general cultural practices should be offered emphasizing rice production under conditions within Afghanistan.

Instructional Contact: Dill Rosh Khan, Rice Botanist at the Swat Agricultural Research station in Mingora is well qualified in rice production. He is a leader in developing varieties tolerant to cold waters and with his knowledge and facilities available to him, would be a good choice to offer this course. The course should be offered in Swat at the Mingora Agricultural Research Station. The Rice Research Institute (part of the Ayub Research Institute program) near Lahore is also a training possibility for now or a later course.

8. Potato Training Program: this program should be scheduled for about two weeks and include training on the cultural practices appropriate to potato production, varieties, 
disease, insect and weed problems, planting dates, harvest and post-harvest storage and the latest information available about potatoes.

Instructional contact: Three possibilities exist for conducting this short course. The NivP AU System has experts in potato production and they could offer a course either in Peshawar or at the Potato Research station in Abbottabad (Contact at $A U$ is Dr. Asrar for course arrangement or at the Abbottabad station, Duri Iman, station Director). A second possibility is the Swiss-Pak project in Mingora/Kalam (contact not known) and the third possibility is the National Agricultural Research Center Training Institute Director Dr. C. A. ozair.

To facilitate the development of short courses, the ADT subject matter personnel should be a part of the planning, implementation and instruction in the course. Pakistan organizations (NWFP AU, NARC, Ayuy Research Institute) have many capable staff but ADT staff should be part of the "short course team" to insure the course meets Afghanistan needs. As an example, in the preparation of a plant Protection/Integrated Pest Management program, the ADT specialist/s in IPM should be involved from planning through instructional and evaluation phases of the program.

The winter (1993) training program for ADT personnel: In planning the 1993 winter training program, only extension officers and agents are included as machinery operators courses were included in the previous years programming. If special training is needed (or desired for machinery operators, the Pak-German program near Multan is recommended). Training is scheduled to begin in early January and run through the first week of March. Approximately 100 participants are expected to participate. The general training schedule follows:

Program offered $/$ group

1. Northern areas training course English language training (optional course for extension officers/managers)

3. Plant protection/IPM course, group 1

4. Plant Protection/IPM course, group 2

5. Water management course, group 1

6. Water management course, group 2

7. Soil fertility/integrated nutrient management course

8. Extension officers and supervisors leadership, management and planning workshop

9. Rice growers update (rice Provinces)

10. Potato growers update

11. Practical seed technology course
Number

20

20

20

20

20

20

20

20

20

20

20 date offered

January 2 .

January

January

February

January

February

February

February

Feb. 28-Mar. 5

Feb. 28-Mar. 5

Feb. 28-Mar. 5 
If this program is to be initiated in the time period suggested, immediate arrangements need to be made for instruction and budget. The NWFP AU can provide much of the instruction and NARC can also help. ADT headquarters personnel specializing corresponding subject matter should work with the provider of instruction and assist with the planning, implementation and instruction. Budgetary planning should take place soon.

\section{Utilization of Pakistan Facilities and professionals for an Instructional/Support Role}

Pakistan has established many centers of expertise which can support the ADT training process. Many of these resources have been used in the past including the cereal crops Research Institute, Pirsabak and the Agriculture Research Institute, Tarnab. Continued use of these centers is encouraged as it is a convenient, effective and appropriate source of training for Afghan agriculturalists. To further facilitate the availability of Pakistan professionals, the following contacts were made during my stay here.

1. NWFP Agricultural University (Peshawar) - ADT has regularly used individuals from the NWFP but not to the extent possible. As we look to more "in depth" training, the AU could be a source of expertise for courses such as Integrated Pest Management, soil fertility, rice production, sustainable agriculture, etc. The NWFP AU system (University and Provincial Research. System) through the USAID funded TIPAN project has sent over 140 faculty members to the U.S. for Ph.D. and M.S. degrees. one-half of these people are back an d provide a source of recent knowledge for training. This is a good source of information and collaboration for ADT.

2. The AYUB Agricultural Research Institute (Faisalabad, and other components of Research in the Punjab). AARI is the most advanced research institute in Pakistan. Research in most areas of crop production is done and many institutes (Plant Protection Institute for example) exist which can provide training. other research institutes in the province also are available (Rice Research Institute, cotton Research Institute, Maize Research Institute for example). Greater use should be made of this expertise. With gasim Yusufi and Dr. Nabi Aslamy, a tour of the facility was made with Dr. Tufail (Director Pulses and Legumes) which included a stops at the programs for wheat, vegetables, document preparation, visual programs and others. Contact with the Institute Director has been made for the offering of short courses for the shura training course (and the Ag. Manager's program). 
3. The Pakistan National Agricultural Research Center (NARC - Islamabad) - The center cocrdinates research for the nation and has a Training Institute complete with hostel) which conducts training courses. The directory of offices and their directors is available to ADT staff and NARC offers a good facility for training and for technical collaboration as they have (in Islamabad) over $100 \mathrm{Ph} . \mathrm{D}$ and over $400 \mathrm{M} . \mathrm{S}$. people).

Many other Pakistan organizations are available to offer training and the Coordinator of Training should continuously be looking for the. In addition, Non government organizations should be watched for expertise that can enhance the ADT program.

\section{Summary and Recommendations}

ADT has a viable network of extension workers inside Afghanistan supported by resource persons in Pakistan. The project provides inputs such as seeds and fertilizers to farmers and the extension agents provide technical assistance to the farmers. Through the annual training program, training is provided to the extension staff. Training to date has been provided to ADT staff to upgrade their knowledge to do their job. Some NGO and shura nominated participants are also programmed for training. In order to enhance their ability to serve, the following recommendations are submitted for consideration:

\section{Training recommendations for ADT extension staff.}

1. Training planning and implementation should be a year around process. Planning for the 1994 winter training session should commence at the conclusion of the 1993 winter training session.

2. A calendar of activities should be prepared for the training program including both training for in-country extension staff and training by in-country extension staff.

3. Training for extension staff should include more specialization as each agent will, in addition to their general role, take on the role of a specialist (plant protection, water management, fertility, etc.)

4. Specialized course offerings should be initiated in the upcoming winter training cycle.

5. Provide more training by ADT extension workers inside Afghanistan. Pakistan based staff can support these efforts. 6. Provide specialized training in management for extension officers and involve them in the program planning for their areas.

7. Provide a general training course (for one month) for the recently appointed agents of the northern areas.

8. Work towards the establishment of "pilot extension centers" to serve as models for future development.

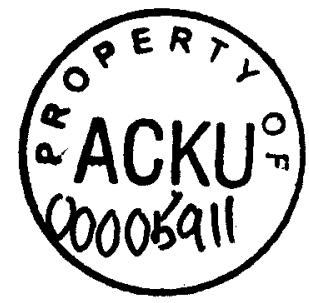


Recommendations regarding training for non ADT employees such as Shura and NGO appointed trainees.

1. When preparing the annual work plan, include non-employee training programs as part of the regular plan.

2. Avoid overilap of employee and non-employee training programs to better utilize staff time.

3. When possible to provide training for potential government of Afghanistan personnel, provide them general training to update their skills and help them to design a strategy for agriculture development in Afghanistan.

4. Appraise non-employee trainees of the ADT efforts in Afghanistan and solicit support to help the program succeed. 5. Develop a continuity of trairing with shura and IGO participants so that training from course to course is coordinated and designed to meet "real needs' of the participants.

Recommendations regarding utilization of pakistan professionals to train ADT clientele:

1. Utilize well-qualified Pakistan sources to provide training to meet program needs.

2. Consider the Ayub Agricultural Research Institute, the National Agricultural Research Center (NARC) and the NWFP Agricultural University and Research system as major resources for training.

3. Utilize other Non government organization personnel to help plan training and to provide instruction when appropriate.

4. When training is being planned buy a Pakistan entity (such as the NWFP AU), involve the corresponding ADT staff for the planning as well as the instructional phase.

5. Continuously try to provide linkages between Afghanistan and Pakistan professional agricultural workers.

Recommendations regarding the strategy for ADT to begin the transition into Afghanistan.

1. Develop pilot extension centers with well trained staff to serve as models for information transfer inside Afghanistan. 2. When possible, work with Afghan government personnel in agriculture to help involve them in the information transfer process.

3. Encourage, as soon as is possible and practical, a survey of the agricultural conditions in Afghanistan to provide better guidance for agricultural inputs.

summary. Selection of training courses for the 1993 ADT winter training sessions should be done immediately so course preparation can be initiated. The counterpart ADT support staff person should provide linkage to the trainers and be a part of the instructional staff where possible. Extension agents should be selected for courses based on the needs of the areas they serve. Well staffed 
and developed extension areas should be selected to serve as pilot centers. Training support and supplies should be provided to facilitate their development. Program planining for the remainder of the year and the 1994 winter training session should commence as the winter 93 training session comes to a close. Program planning should be continuous and supportive of the overall project goals and objectives.

Appendix I.

Summary of Daily Activities of Training consultant Sept. to Nov., 1992

27 \& 28 Sept.: Travel from Macomb, Il. to Islamabad, Pk.

29 Sept.: (Islamabad) Met with personnel of the DAI ADT/AASSP project in Islamabad. Discussed the purposes of the consultancy with Don oelsligle and carried out more detailed planning with Qasim Yusufi

of the training section. Textual materials and reports of the project were collected to assist gaining an understanding of the project.

30 Sept.: (Islamabad) Had visits with Richard Smith, DAI team leader and Ray Renfro of USAID Representative to Afghanistan. Remainder of the day was spent developing a tentative training program to discuss with DAI staff.

1 Oct.: (Islamabad) Read information file summarizing training provided to past courses. Distributed training schedule to personnel (Naik, Aslamy, and Noori) and visited individually with each of them. Following individual visits, a meeting was held with Naik, Aslamy, Noori, and Oelsligle to refine the planned training course. Based on the discussion, refinements to the offerings were made and plans to visit Peshawar on 3 and 4 oct. to discuss past programming with Mary Anne Javed, representative of ATI (Abdul Munaf, Senior Instructor, ATI Peshawar phone 44173 Peshawar) and Ag. University personnel.

2 Oct.: Friday, day off.

3 Oct.: (Islamabad to Peshawar) Left for Peshawar at 6:00 to confer with previous DAI training officer (Mary Anne Javed) and representatives of ATI and the Ag. University. In conference with Mary Anne Javed, discussion of past training and projected future plans were discussed. plans were made to confer with representatives of ATI, NWFP AU, and save the children, U.K. Conferences at the Agricultural University were held with the Deans of crop Production Sciences and Animal Science (Deans Mohammad Karim and Basit Ali Shah), TIPAN personnel and with selected faculty members.

oct. 4: (Peshawar/Islamabad) Met with members of TIPAN Team at NWFP $\mathrm{AU}$ and Faculty and administrative members of the faculty and administration of the AU (Agricultural University) concerning training for Afghan agriculturalists. Met with Mohammad Shafi (Save the Children, U.K.) and discussed tentative training dates for shura and other Afghan agricultural groups. Met with Gul sed Borg of ATI and discussed plans for the shura/NGO trainees. At close of day, returned to Islamabad. 
Oct. 5. (Islamabad) Prepared discussion papers for Shura/NGO nominated Afghan Agriculture trainees. Discussed plant protection programs with Sayed Habib and Haji Wais (DAI cross border advisor). Discussed training program for Afghan agriculture personnel with Haji wais and prepared training plan for aistribution based on his input.

oct. 6: (Islamabad) Prepared tentative training programs for distribution and discussion. Attended meeting of program staff to discuss the proposed training programs for the shura/NGO and other nominated trainees. Worked tó finalize training agendas for the two groups.

oct. 7: (Islamabad) completed topical schedule of both workshops (Shura and Managers workshop). Completed daily itinerary for managers training course.

oct. 8: (Islamabad) Completed itinerary for shura workshop group. Made daily schedule for each sub group of the workshop. Coordinated with Aslamy, Yususfi and others.

oct. 9: Friday, free day.

oct. 10: (Islamabad/Peshawar) Continue scheduling of events for workshop, traveled to Peshawar in afternoon.

oct. 11: (Peshawar) With Aslamy and Yusufi, met with Mohammad Asrar (Continuing Education of NWFP AU) to plan workshop for Afghan managers (interactive program with Ag. Univ., outreach, Extension, Research, and Bureau of Information). Met with Mir Hatam \& Shirin Khan (agronomy) about irrigation training session. Bashir Ahmad (seed technology), Deans Basit Ali Shah and Mohammad Karim (Programming), Dr. Khan Bahadar (plant protection), Jehangir Khan (soil fertility) and others of the Ag. Univ. Discussed training with Aslam Gul of the Swedish Committee and made phone contact with Save the Children. Met with TIPAN Team Leader.

oct. 12: (Peshawar) With Aslamy and Yusufi, met with save the Children U.K. (Mohammad Shafi - arranged 5 training workshops - 3 on community participation and 2 on program management) about management training and community participation workshops and toured Agricultural University Farm with shirin Khan to evaluate machinery for use. Discussed "Agricultural Sustainability Workshop" possibilities with Art Martens of Save the Children, USA. Prepared letter inviting NGO's to participate in a Nov. Dec. training program. Made contacts for tour to Ayub Research Institute in Faisalabad, Pk. Conference with Don Oelsligle.

oct. 13: (Peshawar) With Aslamy, Oelsligle, \& Yusufi, met with NWFP AU Director of Continuing Education (Mohammad Asrar) to get outline for 5 days programming with Agricultural professional workers (extension, research, outreach, and teaching) of the NWFP. Program and budget as prepared and budgeted was satisfactory. With above DAI personnel, met with Deans Karim and Tajammil of NWFP AU regarding programs of Ag. Univ. Worked with Qasim Yusufi and Wally Khan to arrange classrooms for workshops. Evaluated classrooms at ATI, Human resources development, Bureau of Information and other potential sources. Incorporated latest revisions of schedule into managers schedule. 
oct. 14: (Peshawar) Attended ACBAR meeting, met with Don Meiers (AID Rep.), returned to Islamabad and flew to Faisalabad.

oct. 15: (Faisalabad) With Nabi Aslamy and Qasim Yusufi, spent day in Faisalabad at Ayub Agricultural Research Institute, Naeem \& Company, Batala Industries, and following officers of the Ayub Research Institute - Dr. Chaudrey Tufail (host) of the Legume and pulse crops, Dr. Muhammad Hussain, Director of Wheat Program, Dr. Siddiq Chaudrey, Head Vegetable Crops, Director of Training and Publications and other staff. Toured the Ayub Agricultural

Research Institute.

oct. 16: Friday, free day

Oct. 17: (Islamabad) Completed schedule for managers workshop and prepared a partial budget for the program. Prepared schedule for trainers and drafted letters for confirming training dates with Ayub Agricultural Research Institute, Milat, Batala, and Naeem industries. Also, prepared other letters of confirmation for Peshawar based training cooperators.

oct. 18: (Islamabad) completed schedule and budget for Agricultural Manager's Workshop scheduled to begin on oct. 21 in peshawar. Completed scheduling of participating training entities (NWFP Ag. Univ., Ayub Agricultural Research Institute, Naeem, Batala, Milat, Save the Children, and others) for both the manager's workshop and Shura training group. Manager's program postponment notice received at end of day.

Oct. 19: (Islamabad) Notified agencies that had agreed to do training for the Manager's Workshop that the program was postponed. Continued working on Shura Workshop details and commenced planning a strategy of training for current DAI extension workers inside Afghanistan. With Qasim Yusufi, went to the Pakistan National Agricultural Research center to pick up $40 \mathrm{Kg}$. of wheat seed from Ayub Research Institute and toured information transfer, library, tissue culture, weed control and other areas of NARC. Made arrangements for return trip with DAI staff. Met Chairman of PARC and member for crop science (Hannif Qazi) and Crop Science Institute Chair Dr. Hashmi.

oct. 20: (Islamabad)spent most of morning in meeting with Oelsligle, Noori, Yusufi \& Naik discussing the future of training programs in Afghanistan. Programs discussed included the Shura/NGO trainees scheduled for Nov./Dec:, the Managers group (currently under consideration for a later offering) and training for members of ADT who are now working in Afghanistan. spent P.M. developing budget and program for Shura/NGO trainees (150 trainees to begin in program on 22 Nov.)

Oct. 21: (Islamabad) spent morning working on program for Shura/NGO participants. Completed budget for the program. Started work on programs for in-country personnel. Worked with Qasim Yusufi to establish basic parameters for the annual winter ADT training program and commenced work on development of such a plan. Refined the budget for the shura/NGo training program:

oct. 22: Worked to develop a draft training plan for ADT employees. Prepared for trip to Peshawar by making arrangements to see personnel at the Agricultural University (Mohammad 
Asrar) and the Swedish Committee for Afghanistan(Lars Nopp). oct. 23: (Islamabad to Peshawar) Traveled by air to Peshawar for meetings with NWFP $A U$ and other representatives.

oct. 24: (Peshawar) Met with Don Kuhlman (TIPAN Project of AU\}, Dr. Jamal, Masoud and Mehfooz Ali Shah (Outreach Director) (Mohammad Asrar was ill) with Mr. Naik and Yusufi to discuss training programs involving the NWFP AU. Programs planned included the manager's training program, Integrated Pest Management course, fertility course, water management course and an extension course for the shura training program. Met with Horticultural staff to identify contacts for training Afghans in horticulture. Discussed training programs with Deans of crop Production sciences and Animal Science, Chairman of soil science and others. Discussed program in seed technology with Dr. Bashir Ahmad of the NWPF AU. Had conferences on training with members of NWFP AU TIPAN advisors. completed some work on trip report and made further program contacts.

oct. 25: (Peshawar to Islamabad) In early morning met with Arshad Khan, computer technician to install program on computer, worked on training summary and prepared to meet Don oelsiigle who was travelling from Peshawar. Attended meeting with Oelsligle, Naik, Yusufi and samim

with Asam Gul of swedish committee to discuss training possibilities for personnel who might be associated with the Afghan government. Made two trips to save the children, U.K. to see Mohammad shafi about training courses for our programs. Left note for him and will follow up with a phone call about his ability to offer the management program on short notice in the event the manager's course is reinstated soon. Worked on report and flew back to Islamabad.

Oct. 2E: (Islamabad) Made arrangements for tour of NARC by members of the ADT staff. Worked on final report and checked status of return ticket.

With Qasim Yusufi, had an appointment with the NARC Training Institute Director Dr. C. A. Ozair about opportunities for training programs for ADT staff. Conducted literature search of private sector agro-industries at NARC library. Worked with yusufi on rescheduling the program for managers from Kabul, tentatively scheduled (pending shura/NGO invitations) for Nov. 8.

Oct. 27: (Islamabad) Worked on TDY training report. Held meeting with Oelsligle and Noori. Assisted planning for manager's workshop tentatively rescheduled for Nov. 8. Completed draft of TDY report and helped Yusufi prepare letters to notify trainers of the rescheduling ofthe manager's program.

oct. 28: (Islamabad) Finished draft of trip report. continud arrangements for shura programs and had conference with $D$.

Oelsligle.

Oct. 29: (Islamabad) completed work on trip report. Prepared letter of organizations capable of offering courses proposed in trip report. completed rewrite of draft trip report.

oct. 30: Traveled from Islamabad to London. 
Oct. 31: Traveled from London to Peoria, Il. and then on to Macomb.

\section{Appendix II. Draft training program for Afghan Agriculturalists (shura and NGO)}

\section{October 8,1992}

Audience:

Training Program for Afghan Agriculturalists

(Topics by Date)

Approximately 150 Afghan Agriculturalists who have been working in Afghanistan without current access to agricultural training. Nominees will be nominated by local shuras and non government organizations. Participants must be currently working in agriculture and continue to do so following the training. Information about educational background of participants is limited but a varied audience is anticipated.

Training objectives:

Participants will receive updated training in motivation and community participation and agricultural topics to include cereal crops (emphasis), seed production and processing, fertilization, horticultural production and machinery manufacturing and distribution in Pakistan.

Location of training:

NWFP will be the location for the commodity update training and Lahore area the location for the seed processing/distribution update.

Dates of training: Nov. 22 to Dec. 20

Nov. 22 (sunday)

Group 1: 8:00 A.M. to 2:00 P.M.- Save the children, Community Participation course:

3:00 to $4: 30$ P.M. - To be arranged.

Group 2: Potatoes, vegetables, fruit and nursery production. Group 3: Cereal crop production.

Nov. 23 (Monday)

Group 1: 8:00 A.M. to 2:00 P.M. - Save the children, Community participation course.

3:00 to 4:30 P.M. - To be arranged.

Group 2: Potatoes, vegetables, fruit and nursery production.

Group 3: Cereal crop production.

Nov. 24: (Tuesday)

Group 1: 8:00 A.M. to 2:00 P.M. - Save the children, Community Participation course.

3:00 to 4: 30 P.M. - To be arranged.

Group 2: Potatoes, vegetables, fruit and nursery production.

Group 3: Cereal crop Production. 
Nov. 25: (Wednesday)

Group 1: 8:00 to 2:00 P.M. Save the children, community

Participation Program.

3:00 to $4: 30$ P.M. - To be arranged.

Group 2: Plant Protection.

Group 3: Cereal Crop Production.

Nov. 26: (Thursday)

Group 1: 8:00 A.M. to 2:00 P.M. Save the children, Community

Participation Course.

2:00 P.M. to 4:30 P.M. -To be arranged.

Group 2: Plant Protection.

Group 3: Cereal Crop Production.

Nov. 27: (Friday) Free day.

Nov. 28 (Saturday)

Group 1: Lahore field trip.

Group 2: 8:00 A.M. to 4:30 P.M. -Irrigation Program with Mir

Hatam and Shirin Khan (NWFP AU).

Group 3: 8: to 4:30 - Cereal Crop Production.

Nov. 29 (Sunday)

Group 1: Lahore Field Trip.

Group 2: 8:00'A.M. to 2: 00 P.M. Save the children,

Community Participation Course.

3:00 P.M. to 4:30 P.M. To be arranged.

Group 3: 8:00 A.M.to 4:30 P.M. - Extension Teaching Techniques.

Nov. 30: (Monday)

Group 1: Lahore Field Trip.

Group 2: Save the Children, Community Participation course.

Group 3: Extension Teaching Techniques.

Dec. 1: (Tuesday)

Group 1: Lahore Field Trip.

Group 2: Save the Children, community Participation course.

Group 3: Potatoes, fruit, vegetables and nursery production.

Dec. 2: (Wednesday)

Group 1: Lahore Field Trip.

Group 2: Save the children, community Participation course.

Group 3: Potatoes, fruit, vegetables and nursery production.

Dec. 3: (Thursday)

Group 1: Lahore Field Trip.

Group 2: Save the children, Community Participation course.

Group 3: Potatoes, fruit, vegetables and nursery production.

Dec. 4: (Friday) Free day.

Dec. 5: (Saturday)

Group 1: 8:00 A.M. to 4:30 P.M. - Cereal Crop Production.

Group 2: Lahore Field Trip.

Group 3: Irrigation Program with Mir Hatam and Shirin Khan of

NWFP AU.

Dec. 6: (Sunday)

Group 1: 8:00 A.M. to 4:30 P.M. - Cereal Crop Production.

Group 2: Lahore Field Trip. 
Group 3: 8: 00 A.M. to 2:00 P.M. Save the children, Community Participation Course.

3:00 to $4: 30$ P.M. -To be arranged.

Dec. 7: (Monday)

Group 1: Cereal crop production.

Group 2: Lahore Field Trip.

Group 3: 8:00 A.M. to 2:00 P.M. Save the children, community Participation Course.

$2: 00$ to $4: 00$ P.M. -To be arranged.

Dec. 8: (Tuesday)

Group 1: Cereal Crop Production.

Group 2: Lahore Field Trip.

Group 3: 8:00 A.M. to 2:00 P.M. Save the children, community Participation Course.

3:00P.M. to 4:30 P.M. - To be arranged.

Dec. 9: (Wednesday)

Group 1: 8:00 A.M. to 4:30 P.M. -Cereal Crop Production.

Group 2: Lahore Field Trip.

Group 3: 8:00 A.M. to 2:00 P.M. -Save the children, community Participation Course.

3:00 to $4: 30$ P.M. -To be arranged.

Dec. 10, (Thursday)

Group 1: 8:00 A.M. to 4:30 P.M. Cereal Crops Production.

Group 2: Lahore Field Trip.

Group 3: 8:00 A.M. to 2: 00 P.M. -Save the children,

Community Participation Course.

3:00 to 4:30 P.M. -To be arranged.

Dec. 11: (Friday) Free day.

Dec. 12: (Saturday)

Group 1: 8:00 A.M. to 4:30 P.M. -Irrigation Program with Mir

Hatam and Shirin Khan of NWFP AU.

Group 2: 8:00 A.M. to 4:30 P.M. -Cereal Crops production.

Group 3: Lahore Field Trip.

Dec. 13: (Sunday)

Group 1: 8:00 to 4:30 P.M. -Plant Protection.

Group 2: 8:00 A.M. to 4:30 P.M. - Cereal Crops Production.

Group 3: Lahore Field Trip.

Dec. 14: (Monday)

Group 1: 8:00 A.M. to 4:30 P.M. -Plant Protection.

Group 2: 8:00 A.M. to 4:30 P.M. - Cereal Crops Production.

Group 3: Lahore Field Trip.

Dec. 15: (Tuesday)

Group 1: 8:00 A. M. to 4:30 P.M. - Extension Teaching Techniques.

Group 2: 8:00 A.M. to 4:30 P.M. -Cereal Crops Production. Group 3: Lahore Field Trip.

Dec. 16: (Wednesday)

Group 1: 8:00 A.M. to 4:30 P.M. -Extension Teaching Techniques.

Group 2: 8:00 A.M. to 4:30 P.M. - Cereal Crops Production.

Group 3: Lahore Field Trip. 
Dec. 17: (Thursday)

Group 1: 8:00 A.M. to 4:30 P.M. -Potatoes, Vegetables, Fruit and Nursery Production.

Group 2: 8:00 A.M. to 4:30 P.M. -Cereal Crops Production. Group 3: Lahore Field Trip.

Dec. 18: (Friday) Free day.

Dec. 19: (Saturday)

Group 1: 8:00 A.M. to 4:30 P.M. -Potatoes, Vegetables, Fruit and Nursery Production.

Group 2: 8:00 A.M. to 4:30 P.M. -Extension Teaching Techniques.

Group 3: 8:00 A.M. to 4:30 P.M. - Plant protection.

Dec. 20: (Sunday)

Group 1: 8:00 A.M. to 4:30 P.M. - Potatoes, Vegetables, Fruit and Nursery Production.

Group 2: 8:00 A.M. to 4:30 P.M. - Extension Teaching Techniques.

Group 3: 8:00 A.M. to 4:30 P.M. - Plant Protection.

Dec. 21: (Monday) - Graduation - All groups.

End of Program 
Appendix III. Proposed Budget for Shura/NGO Personnel

October 21, 1992

To: Sherali Khan Basharat

From: Qasim Yusufi, Training Coordinator

Rodney J. Fink, Training Consultant

Through: Mohd. Arif Noori \& Don Oelsligle

Re: Budget for shura/NGO agricultural update training

1. Program summary: The training program for 150 agricultural workers from Shura and NGO groups is scheduled in Peshawar from Nov. 22 to Dec.21. Expected participants from inside Afghanistan include 100 from shuras and 50 from non-government organizations(NGO's). The proposed budget is planned for 150 participants for 35 days (including travel days). The shura participants will receive a stipend of Rs. 300/day. The participants from NGO's will receive a stipend of Rs. 60/day while in Peshawar and Rs. 300/day while on the field trip to Lahore. The following budget should cover the program although firm prices have not been received for some items such as bus rental and programming expenses:

\section{proposed Budget}

Budget Explanation

1. Stipend - Shura participants - 36 days

$\mathrm{X} 100 \mathrm{X}$ Rs. 300/day $=1,080,000$

NGO participants - in Peshawar and in

travel - 29 days $\times$ Rs. $60 \times 50=87,000$

NGO participants on Lahore trip -

7 days $\mathrm{X}$ Rs. $300 \times 50$ participants $=105,000$

2. Transportation for participants to/from

Peshawar - 150 X 1500 rs. $=225,000$

3. Transportation during course including

field trip to Lahore

Rs.3,000/day X 9 vehicles $\times 7$ days $=189,000$

Rs. 1,500/day $X 9$ vehicles $X 20$ days $=270,000$

4. Community Participation for Extension workers

(Save the Children U.K.) $150 \mathrm{X}$ Rs. $500=75,000$

5. Daily teas - 165 persons X Rs. 4 X 27 days 17,820

6. Graduation ceremony - 200 persons

times rs. $50=10,000$

7. Classroom rent-chairs, rooms, etc. 25,000

8. Programing costs for Lahore trip -

7 days $x$ rs. 1,500/day $=10,500$

9. Stationery, notebooks and misc.

training supplies - Rs. $120 \times 150=18,000$

10. Miscellaneous expenses
Total projected cost: Rs. 2, $\frac{20,000}{132,320}$ 
October 21, 1992

Shura/NGO workers budget, page 2

2. other program needs: During the program the following support is needed from DAI staff:

A. Two tea boys throughout the training sessions.

B. Three office vehicles dedicated throughout the program. Each vehicle will be accompanying the field trip to Lahore for 1 week.

C. Advance stipend payment for 17 days to the participants on Nov. 22 ( 17 days stipend = Rs. 635,000) and the remainder (Rs. $637,000)$ and travel expense (Rs. 225,000) should be paid on Dec. 19 .

D. Cash advance of at least Rs. 10,000 per week should be made available to the Training coordinator, or someone designated by him, for tea, travel allowances, emergency and other expenses.

E. Arrangements must be made for issuance of temporary identification cards on Nov. 22.

3. To facilitate the operation of the program, authorization for Peshawar office (Wali Khan/Saadat) to make payments is needed.

Copies Provided: Mian Sahib, Saadat, Wali Khan 
Appendix IV. Program for Afghan Managers (tentative, now on hold).

PROGRAM OUTLINE FOR AFGHAN AGRICULTURE MANAGERS

oct. 21

oct. 22

$8: 25:$

$8: 30:$

$8: 45:$

$9: 30:$

$10: 15:$

$10: 45:$

$11: 15:$

$11: 45:$

$12: 15:$

$12: 40$ :

1:00:

$2: 30:$

oct. 23

oct. 24

$8: 30$

$9: 00$

10:00

$10: 30$

$12: 00$

oct. 25

8:00:

8:05:

$8: 15:$

$8: 45$ :

$9: 15$ :

$10: 15:$

$10: 45:$

$11: 15$ :
Wednesday: Participants arrive in Peshawar and check in with DAI office for instructions.

Thursday: DAI office, Introductory/welcoming session:

Recitation from the Holy Quran

Welcome and orientation of ASSP Program by Richard smith

Agricultural Development and Training - Mohd. Arif Noori

Training programs - Qasim Yusufi

Machinery programs - Ghafary

Tea break

Horticultural work - Anwar Malham

Plant Protection - Sayed Habib

Wheat program of SCA - Azum Gul

Poultry activities - Sayar

Program Guidelines, administrative details (per diem, scheduling, housing, expectations, etc.) Qasim Yusufi and Saadat Hussain.

Adjourn.

Friday, participants on their own.

saturday, DAI office.

Cereal crops program discussions - N. Aslamy

Group discussions

Tea break

Agricultural extension discussions - A. Naik

Adjourn

Sunday, (NWFP Agricultural University main campus) Recitation from Holy Quran

Introductions and program orientation - Qasim Yusufi

Overview of the NWFP Agricultural University system - Abdur Rehman Khan.

Tea break

Background of agricultural education in NWFP Basit Ali Shah.

Collaborative work with University of Illinois, TIPAN, Dr. Oval Myers, Jr.

Tea break.

The NWFP cereals, demonstration and research 
12:30: $\quad$ Technology transfer in the

oct. 26 Adjourn

8:00: Agricultural Training Institute(ATI) facilities Gul sad Borg, ATI.

9:00: The work of the NWFP Agricultural Extension service - Muhammad Akram Khan.

10:00: Facilities and services of the Agricultural

Information Bureau - Gulnawaz Khan Khattak.

11:00: Tea Break

11:30: Integrated pest management in Plant protection in

12:00: WWFP - Dr. Nasser Hussain. $\quad$ weed problems and control in the NWFP - current work and strategies for the future - Dr. Khan Bahadar Marwat

1:30: Importance of effective water management practices in the NWFP - Dr. Jamal.

2:30: Adjourn.

Oct. 27

$8: 00:$

Tuesday, Agricultural Research Institute, Tarnab.

overview of research facilities and activities of the Agricultural Research Institute, Tarnab - Abdur Rauf Khattak.

9:00 to 2:30 - The participants will be divided into 4 groups

and each cover the following four topics:

Group 1: soil fertility research and recommendations.

Group 2: Horticultural research and recommendations.

Group 3: Oil seed crops research and recommendations.

Group 4: Plant Protection research and

2:30: Adjourn.

oct. 28

$8: 00:$

Wednesday, cereal crops Research Institute, Pirsabak

$8: 30:$

$10: 00:$

$11: 00:$

What is the CCRI, Abdul Wadud Khan, Director. Wheat seed production - Ali Haider.

Maize seed production - Dr. Mohammad Saleem \& Dr. Kiramat.

Tea Break

11:30 to 230: The participants will be divided into three groups that will rotate through the following three topics:

Group 1: Tillage and seeding equipment.

Group 2: Seed processing and storage equipment.

$2: 30:$

Field observations of maize and wheat. 
oct. 29 Thursday, Location, NWFP AU main campus.

8:00 to 10:00: Two groups to be rotated for one hour as follows:

Group 1: Malakandher farm visit.

Group 2: Farm equipment at the Malakandher

farm with Ghafary.

10:45: Open discussions. in departments of interest to participants (Soil Science, Agronomy, Plant

$12: 30: \quad$ Adjourn.

oct. $30 \& 31$ Friday \& saturday: Free time, participants on their own.

Nov. 1 - 5 sunday through Thursday:

Group 1: Tour agricultural organizations of the Quetta area (Agricultural Research Institute, Arid Zone Research Institute, others).

Group 2: Attend program management workshop with save the children Fund, U.K. in Peshawar.

Nov. $6 \& 7$ Friday \& saturday: Free time (except for those traveling to a field trip site).

Nov $8-12$ sunday through Thursday:

Group 1: Tour agricultural organizations of the Faisalabad and Lahore areas (including Pioneer, Cargill, Ayub Research Institute, machinery companies and others).

Group 2: Tour agricultural organizations of the Quetta area (Agricultural Research Institute, Arid Zone Research Institute, others).

Nov. 13 \& 14 Friday \& saturday: Free time (except for those traveling to or from a field trip site).

Nov. 15 - 19 sunday through Thursday:

Group 1: Attend program management workshop.

Group 2: Tour agricultural organizations of the Faisalabad and Lahore areas (including Pioneer, Cargill, Ayub Research Institute, Batala, Naeem, others).

Nov . 20

Friday: Free day

Nov. 21

Saturday: Final debriefing session of workshop participants. The summary session will provide an opportunity for reviewing the program by ADT staff with participants. 
Appendix V. Budget summary for Afghan Managers Program.

October 18,1992

To: Sherali Khan Basharat

From: Qasim Yusufi, Training Coordinator

Rodney J. Fink, Training Consultant

Through: Mohd. Arif Noori \& Don Oelsligle

Re: Budget for Afghan Managers training course

1. Program summary: The training program for agricultural managers is scheduled from oct. 21 to Nov. 21 . The proposed budget is planned for 65 participants for 34 days (including 2 travel days). During the first week, participants will be trained together with coordination help of the NWFP Agricultural University. For the remainder of the course, each participant will participate in a program management workshop (one week), and take two week trips (one week each) to Lahore and to Quetta. orientation (Oct. 21 to 24) and debriefing (Nov. 2l) sessions will be held by DAI staff in Peshawar. The following budget should cover the program although firm prices have not been received for some items such as bus rental and programming expenses:

\section{proposed Budget}

Budget Explanation

1. Stipend - 34 days, 65 participants

times rs. $400 /$ day

2. Transportation for participants from

Kabul/Peshawar/Kabul - 65 X rs. 400

3. Transportation during course including

field trips to Lahore \& Quetta

Rs. 3,000/day X 4 vehicles X 16 days

Rs. 1,500/day X 4 vehicles X 14 days

4. Save the Children U.K. Program Management course - 65 x rs. 500

5. Program arrangements by the NWFP AU 5 days programming

6. Daily teas - 75 persons $X$ rs 4 X 30 days 9,000

7. Graduation ceremony - 100 persons
times rs. 50
8. Classroom rent-chairs, rooms, etc.
5,000
3,500

9. Programming costs for Quetta field trip-

7 days $X$ rs. 1500/day

10. Programming costs for Lahore trip -

7 days $X$ rs. 1,000/day

11. stationery, notebooks and $\mathrm{misc}$. training supplies
Amount, rupees

$$
\begin{array}{r}
884,000 \\
26,000 \\
192,000 \\
84,000
\end{array}
$$

32,500

31,325

10,500

7,000

$\underline{6}, 50 \underline{0}$

Total projected cost: Rs. 1,291,325 
2. Other program needs: During the program the following support is needed from DAI staff:

A. One tea boy for the following days: Wednesday, Thursday and Saturday october $21,22 \& 24$.

B. Two office vehicles dedicated throughout the program. Each vehicle will be accompanying the field trips to quetta and Lahore for 2 of the 4 weeks.

C. Advance stipend payment to the participants on oct. 21 (17 days stipend $=$ Rs. 442,000) and on Nov. 19 (17 days stipend $=$ Rs. 442,000 ).

D. Payment of Rs. 13,000 (on oct. 21), bus rental for delivery of participants from Kabul to Peshawar.

E. Cash advance of at least Rs. 10,000 per week should be made available to the Training coordinator, or his designee, for tea, travel allowances, emergency and other expenses.

F. Arrangements for issuance of temporary identification cards have been made.

3. To facilitate the operation of the program, authorization for Quetta (Col. Sadullah Khan) and Peshawar (Wali Khan/Saadat) to make payments (as has been the past practice) is needed.

Copies Provided: Mian Sahib, Col. Sadullah Khan, Saadat, Wali Khan

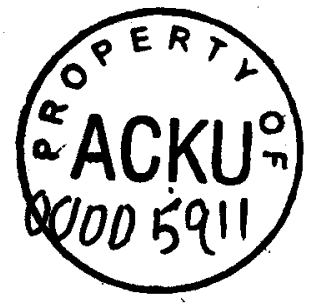

